\title{
Modern translucent materials and their impact on architectural forming
}

\author{
Anastasiya Timina, Regina Yanova, Aleksey Popov*and Tatyana Sorokoumova
}

Moscow State University of Civil Engineering, Yaroslavskoe shosse, 26, Moscow, 129337, Russia

\begin{abstract}
This work is devoted to the use of load-bearing elements made of translucent materials. To confirm the relevance of the study, regulatory materials and similar practices of using various materials as vertical and horizontal bearing elements were studied. Experimental experience was conducted to identify high indicators of the required characteristics of elements, which are considered as independent supporting structures. The object of the research is modern translucent materials. These materials have proven themselves as walling and auxiliary elements, their use as a supporting structure is not so important. However, in the course of the study it was revealed that translucent materials can be used as bearing elements without loss of strength and stability of the structure, which allows to visually facilitate the architectural appearance of the building. The subject of research is the influence of translucent supporting structures on the architectural shaping and the formation of the urban environment, by means of using the most visually lightweight structures. As a result of the study, it was concluded that it is possible and attractive to use translucent structures as load-bearing elements; however, there are drawbacks in a number of technological limitations, which directly affects the advantage of choosing not to benefit from translucent materials.
\end{abstract}

\section{Introduction}

The development of science and technology, the emergence of new designs and materials has always had a decisive influence on the architectural form. As the spread of arch and vault structures in ancient Rome determined the architectural appearance of buildings and structures throughout the empire for centuries, the emergence of reinforced concrete in the 19 th century changed the face of world architecture, so perhaps the 21 st century will change beyond recognition.

At present, both new technologies for enhancing the mechanical properties of traditional glass and new chemical compositions of durable translucent polymers are being introduced into production [1].

Light transmitting building materials are the result of innovative and expensive construction technologies. For over 50 years, concrete has been the most popular building material. Due to its high strength, density and resistance to temperature extremes, concrete foundations last the longest. But, this material has rather poor aesthetic indicators, which

\footnotetext{
* Corresponding author: da945@yandex.ru
} 
significantly narrows the scope of its use in construction. To solve this problem, transparent concrete was developed (or as it is also called light transmitting or LiTraCon). This is an innovative material that is just beginning to conquer the market.

This modification was developed by the Hungarian architect Aron Lošonci, who experimented with building materials. With his light hand, light-conducting concrete was born 15 years ago [2]. Its main composition is a composite material based on cement and fiber-optic filaments, the matrix of which is a high-strength cement mortar or concrete. A number of optical fibers are embedded in matrix material with a specific spatial arrangement. Unlike the transfer mechanism of organic composite materials, which is determined by the matrix materials, the light-transmitting material relies on extensive optical fibers that transmit light between the two sides of the blocks [3].

\section{Methods}

To determine the prospects for the use of the considered materials in comparison with the traditional ones used for the elements of supporting structures, it is necessary to analyze a number of experimental data in order to identify the necessary high indicators of the required characteristics. For example, for translucent concrete, glass and polymer elements - light transmitting properties and the ability to perceive high loads, respectively.

In practice, two types of optical fibers LTC are used [4]: vitreous fibers with a diameter of $70 \mathrm{~lm}$, and polymeric fibers with diameters of $1 \mathrm{~mm}$ and $3 \mathrm{~mm}$. The fibers were preprocessed before preparation, to make the fibers bended adequately. Textile process, such as knitting and warp/weft yarn, was utilized to form a layered fabric. Aggregate of self-compacting concrete was gravel with maximum size of $6 \mathrm{~mm}$. The fibers were fixed in concrete evenly. Fiber-concrete was an ideal layered composite, and between the fabrics were the layers of concrete. The volume fraction of fiber was $3-6 \%$. The blocks were cut and polished after demoulding, and light transmitting concrete with different sizes could be obtained.

There are two types of fixation methods of optical fiber fabric with the mold:

Method A: The parallel steel bars, which are in the direction of the long axis of uncovered end, are fixed into the mold at a specific designed distance. The optical fiber fabric is twined in bars, the bars are attached on both the bottom and the top of the mold, and the optical fiber fabric is straightened by the bars.

Method B: Steel bars, which are in accordance with desired figures, are embedded into the base of uncovered wooden mold. The twining optical fiber fabric can be formed in designed shapes.

The light transmitting properties of LTC were measured by optical power meter, which is used to measure the optical power of optical energy through optical fibers or absolute optical power of light, and to evaluate the transmission quality of optical fibers. The apparatus includes a stable light source, a detector and a display. The diameter of detection surface of the detector is $1 \mathrm{~cm}$. In this study, the optical power meter was used to measure the optical power of LTC at various distances between LTC and the light source. The light sources were white light and monochrome red light (wavelength $=633 \mathrm{~nm}$ ).

The light transmittance of LTC was measured by an optical power meter. It should be noticed that the detector of $1 \mathrm{~cm}$-diameter-range measured the transmitted light from 1 to 4 optical fibers of the specimens. The results were given in Figs. 1 and 2, respectively. The LTCM samples using optical fibers with diameters of $1 \mathrm{~mm}$ and $0.5 \mathrm{~mm}$ were labeled as Sample A and B, respectively. [5]. 


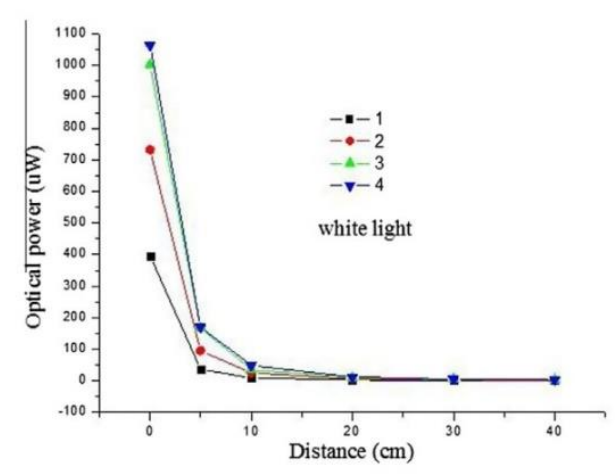

(a) White light

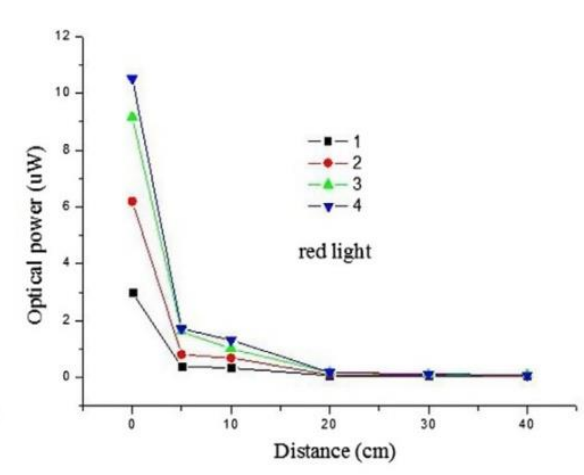

(b) Red light

Fig. 1. The optical power contrast between various number of fibers under white and red light (Sample A).

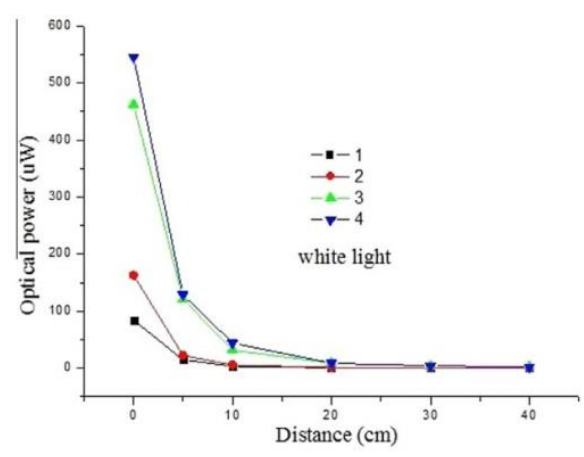

(a) White light

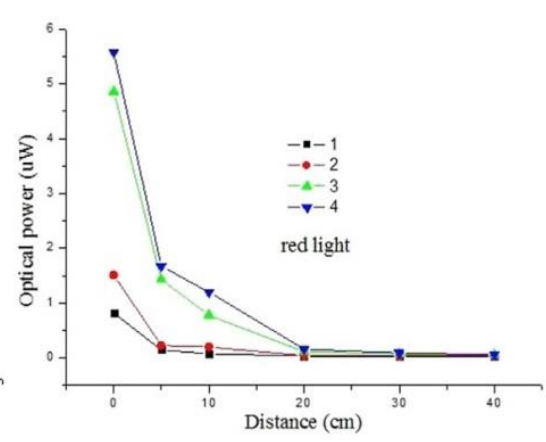

(b) Red light

Fig. 2. The optical power contrast between various number of fibers under white and red light (Sample B)

From Fig. 1-2, for samples A and B, it can be concluded that the optical power decreases with increasing distance from the light source to the sample, since The number of fibers is a determinant, regardless of white or red light. In addition, initially the optical power for the two samples is reduced equally, and then the rate of reduction of optical power gradually decreases and, eventually, almost becomes the same. For samples at the same distance, the optical power gradually increases with the number of fibers in the sample.

It should be noted that LTC, can be used in wide applications, it has excellent lighttransmitting properties, good mechanical properties and universal decorative effects.

The strength characteristics of such a material are undoubtedly greater than the corresponding characteristics of glass, but the strength of glass can also be improved by changing the production technology, as well as when combining it with other materials - for example, with wood. One of such elements of the supporting structure is a composite beam.

In order to reveal the high indices of the necessary properties, an experiment was carried out, for which composite beams and glass walls and wooden bars separately composing them were taken as samples. All samples had a length of $1800 \mathrm{~mm}$ and were subjected to 4-point bending according to EN 12150-2 [6]. The wall of the composite beam was made of ordinary (thermally polished) glass and bonded to the wooden edges with the 
help of acrylate glue. As a result of the tests, a diagram was obtained of the dependence of strain on load (Fig. 3).

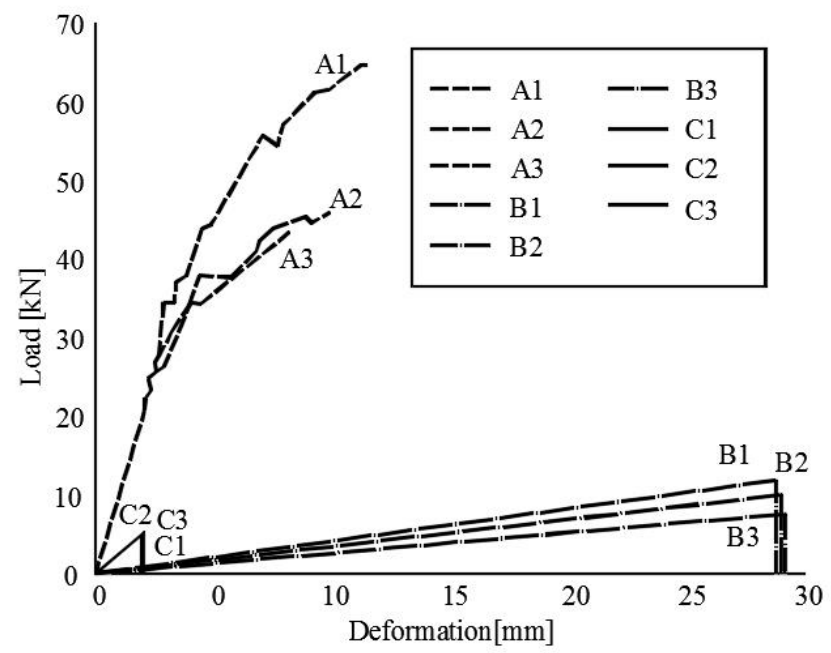

Fig. 3. Load strain chart for:

A1-A3 - composite beam,

B1-B3 - two wooden edges;

C1-C3 - glass beams.

As can be seen from the diagram, the composite work of the elements of the hybrid beam, connected by acryl glue, provides a solid bearing ability capable of perceiving many times the sum of the maximum loads perceived by the two wooden edges and the glass beam.

\section{Results and Discussions}

Mostly translucent concrete, glass and polymer elements used for load-bearing structures are used in the latest architectural compositions for decorative purposes, for the realization of bold design solutions in urban design, for creating original interior elements. Until now, the freedom of action of design engineers, designers and artists is limited only by the high cost. The solution to this problem will lead to the emergence of many amazing innovative forms.

The evolution of the architectural typology of buildings and structures depends on many factors that make up the global and local social and economic systems, which in many respects are the engines of scientific and technological progress. And they are also the reason for increasing the choice of innovative technological solutions for modern possibilities of developing an optimal design solution for almost any urban planning situations, climatic conditions and resettlement schemes.

An interesting example of using glass as a carrier element is the Pavilion Talus du Temple near the French town of Noyers (architect Dirk Jan Postel). Part of the wall is made of float glass panels (Fig. 4.). The wooden roof rests on them. The connection of roof and float glass panels is made with steel corners with neoprene gaskets. 


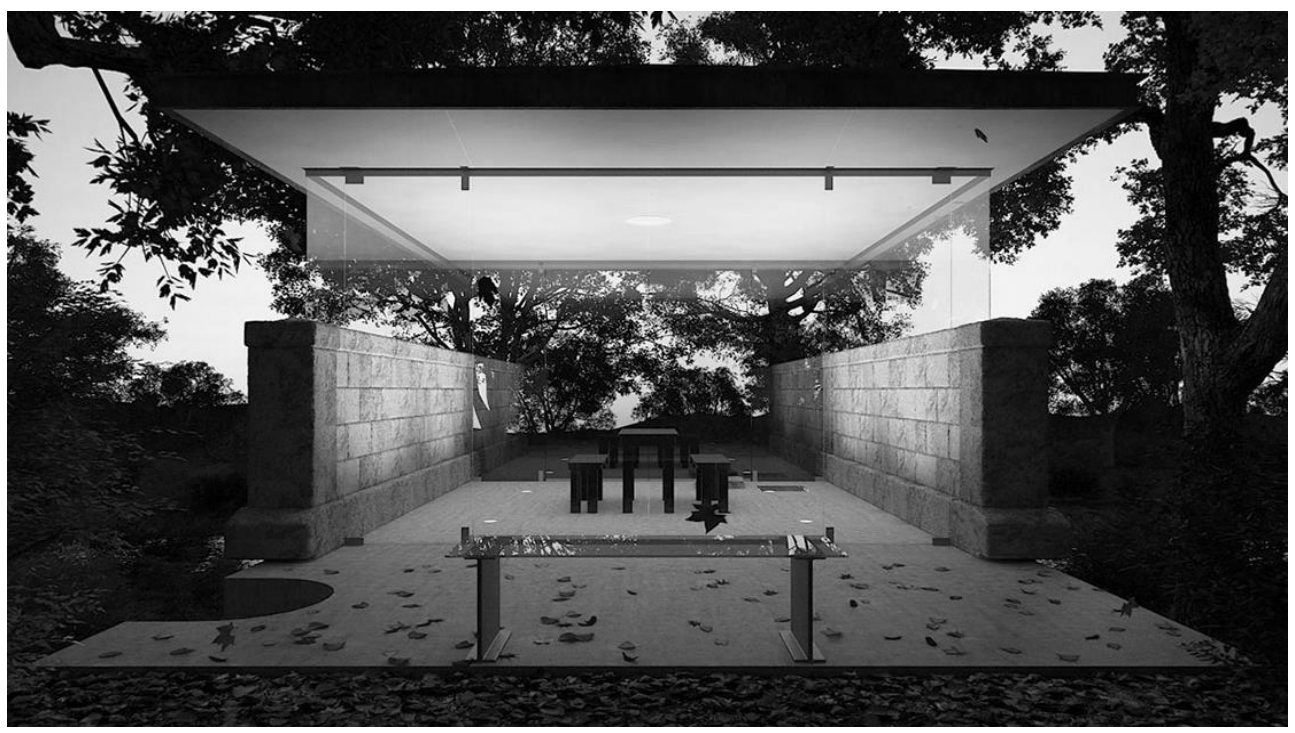

Fig. 4. Pavilion Talus du Temple. Burgundy region - Franche-Comte, France.

305 metal columns support the frame of the glass workshop pavilion (fig. 5.), that was built for Kanagawa Institute of Technology (Japan) by architect Junya Ishigami. The walls and their supporting ribs are made of glass. The peculiarity of this pavilion is its high strength, which was achieved due to the non-rigid mounting of the glass to the metal frame - there are backlashes and gaps. These measures were taken due to the high level of local seismicity.

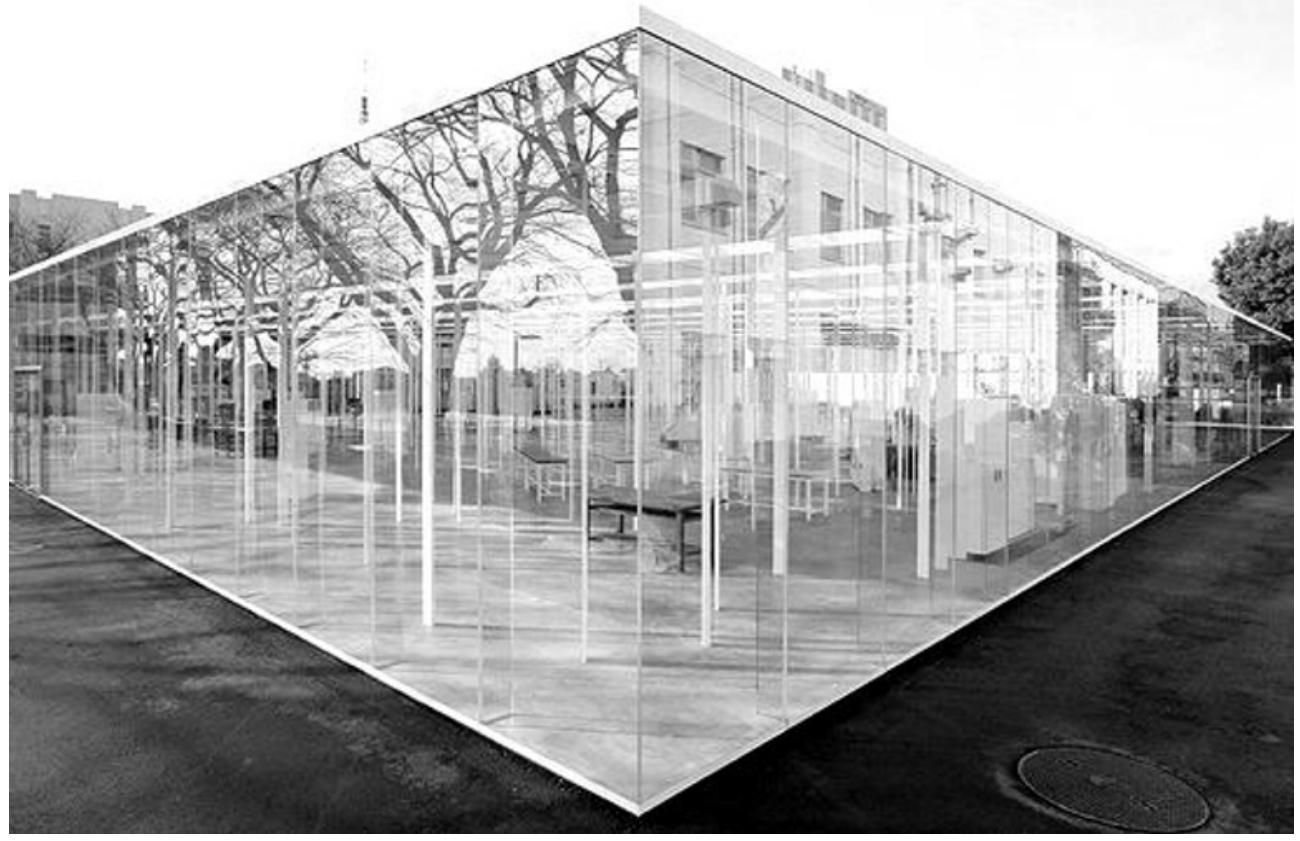

Fig. 5. Workshop of the Kanagawa Institute of Technology. Kanagawa Prefecture, Japan. 
An interesting example of using the supporting translucent structures is the building of the Podlaskie Opera and Philharmonic Theater in Bialystok, Poland, which is currently acquiring an increasingly important role as a cultural center in the eastern part of Europe.

It seems that the building grows out of a green hill, sometimes merging with it, forming a whole with the relief. This effect was achieved through the use of a number of interesting architectural and design solutions. So one of the facades of the theater is completely made of glass columns-edges and glass elements of the fencing - panels. Vertical column ribs are presented in the form of float glass panels $2.3 \mathrm{~m}$ high and 10 millimeters thick. The connection of the walls with the base and the roof is made with the help of steel corners with gaskets made of polymeric materials.
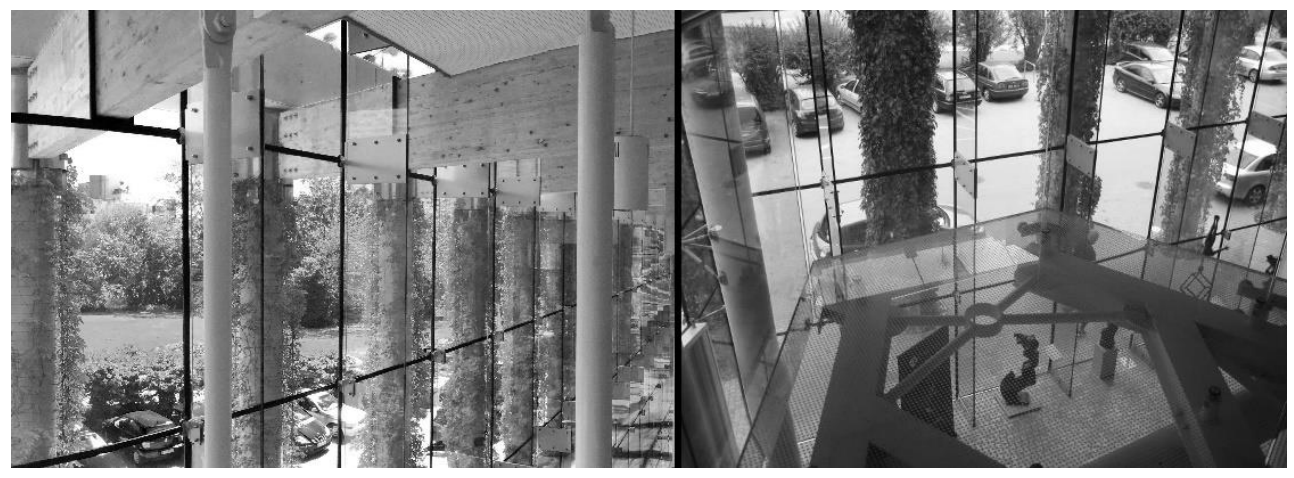

Fig. 6. The glass facade of the building of the Podlaska Opera and Philharmonic Theater. Bialystok, Poland.

These practical examples prove that modern glass is applicable both in compressed and stretched structures, and even in bending structures (Fig. 7). At the moment there are certain difficulties associated with the methods of calculating such structures, however many research centers are working to study the behavior of glass and translucent polymeric materials under load and are developing technologies to improve their carrying capacity.

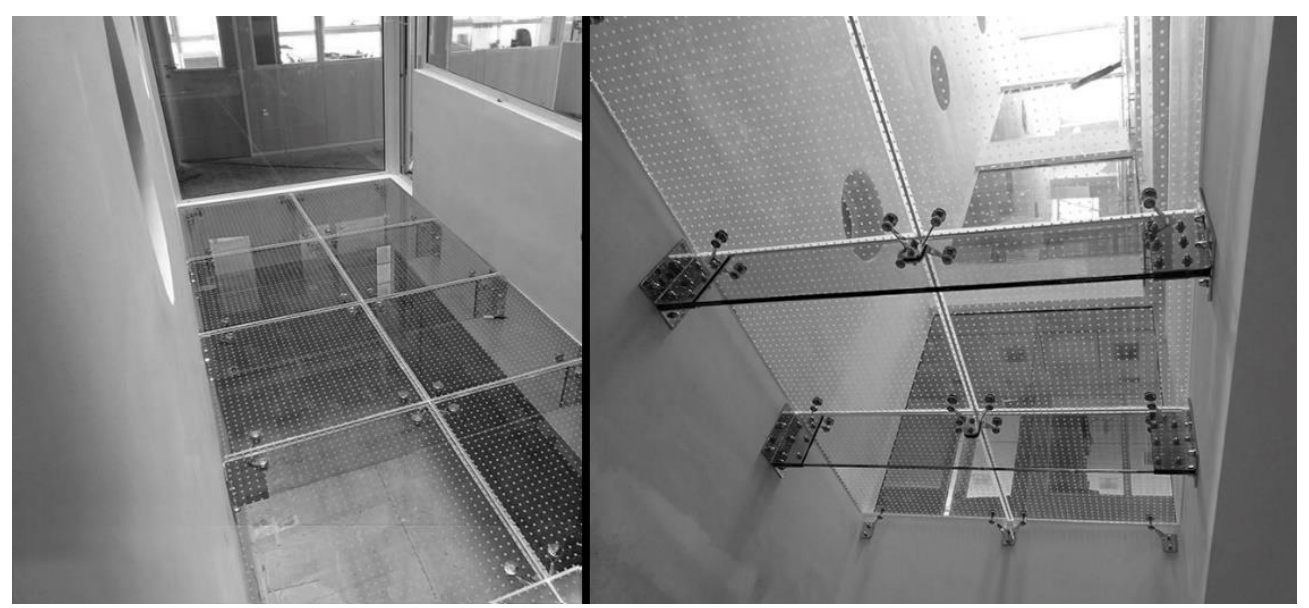

Fig. 7. Overlapping of the corridor along the glass beams of GLASSCON GmbH. 
The use of LiTraCon concrete has now gained wide popularity among architects both in the field of low-rise construction and in industrial construction. Transparent concrete blocks fit perfectly into the structure of buildings in the modern and high-tech style.

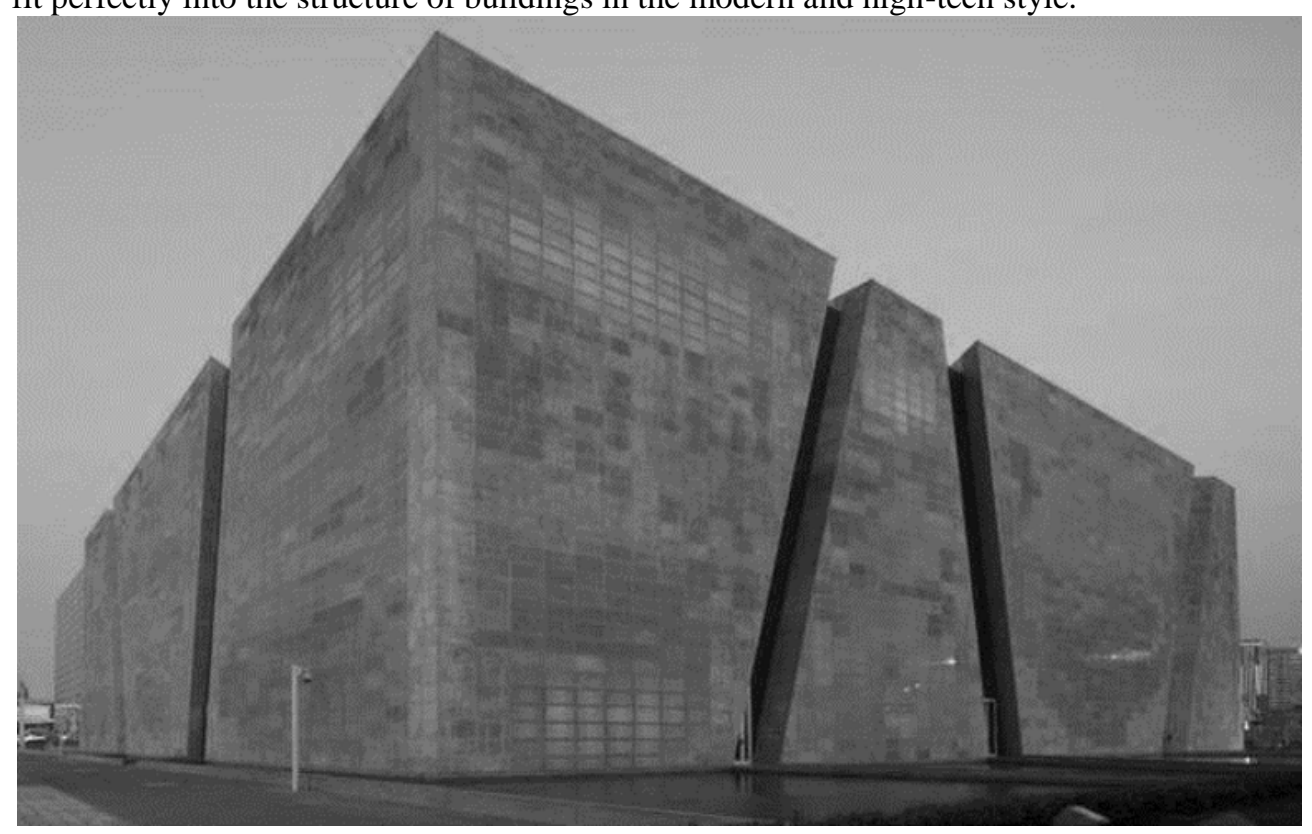

Fig. 8. Office building with walls of translucent concrete.

\section{Conclusions}

Translucent supporting structures that meet the requirements of modern aesthetics of urban residential and public buildings, can give the object even greater lightness, weightlessness. Such constructions make it possible to create an environment isolated from external space, perceived, however, as its integral continuation.

In some cases, the use of translucent materials, in particular glass, allows the most "painless" to include modern buildings in the existing buildings. Interesting features of such materials are not only the ability to transmit light, but also to form on their surface multiple highlights and reflections changing in time.

The artistic and aesthetic qualities laid down in the material determine the constant appeal to him of architects all over the world. There are strong human associations with such material as glass- modernity, clarity, conciseness, adaptability [7].

In this way, new durable translucent materials open up opportunities for architects.

Currently, it is technologically possible to use carrying translucent elements of only simple geometric shapes, which limits the possibilities of architectural shaping. Buildings and their individual fragments, designed with load-bearing structures made of various types of glass, are now limited to modest dimensions due to the nature of the material.

The technology of interfacing elements with each other makes it extremely difficult to use curved shapes. However, technical progress in the near future may make it possible to use complex glass shells, bionic translucent polymer structures, etc., which may entail revolutionary changes in world architecture. 


\section{References}

1. A.G. Gogin, Collection of: research and development a collection of materials of International scientific-practical conference Cheboksary. Bearing structures from glass 2016 69-71 (2016)

2. http://vest-beton.ru/stati/svetoprozrachnyj-beton.html

3. Babaeva N.A., Lustina OV, Kupchekov A.M. Transparent concrete // Young Scientist 17 (121), 19-21. (2016)

4. A. Roye, M. Barle, S. Janetzko, T. Gries, Faser-und textilbasierte Lichtleitung in Betonbauteilen-Lichtleitender Beton, Beton- und Stahlbetonbau 104 (2) 121-126. (2009)

5. Li Y., Xu Z.Y., Gu Z.W., Research on the light transmitting cement mortar, Adv. Mater-Res. 450-451, 397-401. (2012)

6. DIN EN 12150-2:2005-01

7. Zenkova K.V. Shaping in ecological architecture / K.V. Zenkov // Art and Culture 4 (28), 48-51. (2017)

8. M. A. Demyanenko, P. V. Stratii, System technologies Design Of bearing structures of glass 1 (26), 168-172. (2018)

9. K. V. Zenkov, Art and culture Shaping in environmental architecture 4 (28), 48-51. (2017)

10. I. B. Melnikova, Integration, partnership and innovations in construction science and education Compositional options solid facade glazing in the residential architecture 15, 71-77 (2015)

11. I. S. Rodionovskaya, E. Dorozhkina, Urbanism Ecology of urban areas in the aspect of "green architecture" and landscaping 2, 11-19 (2017)

12. L.A Golovanova., A.S. Eroshenko, Scientists Notes PNU Particular qualities energyefficient translucent enclosing constructions 4, 63-70 (2014)

13. A.V. Popov, International Journal of Civil Engineering and Technology (IJCIET) Historical Development Stages of the Student Youth Accommodation Architecture from Dormitories Prototypes to Post-industrial University Campuses 9(11), 2526-2536 (2018)

14. A.V. Popov, Advanced Materials Research Ecological Optimization of the Architectural Environment of Higher Education Institutions in Moscow - The Use of Phyto-Metal Structures 869-870, 162-166 (2014)

15. O. Gerasimova, I. Melnikova Podium landscape of residential zones IOP Conf. Ser.: Mater. Sci. Eng. 365, 022013 (2018)

16. E. Shcherbina and M. Slepnev Scientific Rev., The system of town planning regulations for sustainable development of territories 6, 240-244 (2016)

17. Aly Hassan, Mohamed Maher Shahin, Mahmoud Morsy Alexandria Engineering Journal 50(4), 367-380 (2011)

18. E. I. Batov, Procedia Engineering The Distinctive Features of "Smart" Buildings, 111, 103-107. (2015)

19. N. A. Babaeva, O. V. Lustina, A. M. Kopchenov, Young scientist Transparent concrete, 17 (121), 19-21 (2016)

20. J. Hulimka and M. Kozłowski ACEE Journal Load-bearing capacity of hybrid timberglass beams, 2, 61-62 (2014). 
21. P. Cruz, Pequeno J. Challenging Glass Conference Timber-Glass Composite Beams: Mechanical Behaviour and Architectural Solutions, 08, 439-448 (2008)

22. K. Kreher and J. Natterer Structural Engineering International Timber-GlassComposite Girders for a Hotel in Switzerland, 14, 149-151 (2004)

23. N. E. Putintsev, Collection of reports of the forum of the Department of design of buildings and structures of the Institute of construction and architecture Review of experimental studies of a hybrid glass and wooden beams, 30-35 (2017) 